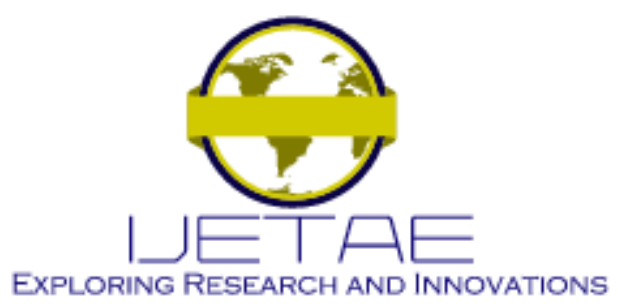

International Journal of Emerging Technology and Advanced Engineering

Website: www.ijetae.com (E-ISSN 2250-2459, Scopus Indexed, ISO 9001:2008 Certified Journal, Volume 11, Issue 12, December 2021)

\title{
Blockchain in Technogenic Safety and Risk Management
}

\author{
S. V. Shaytura ${ }^{1,2}$, L. A. Olenev ${ }^{3}$, A. A. Nedelkin ${ }^{4}$, A. M. Minitaeva ${ }^{5}$, K. V. Ordov ${ }^{6}$, V. M. Feoktistova ${ }^{7}$ \\ ${ }^{1}$ Russian State University of Tourism and Service, Russia; ORCID 0000-0002-5621-5460 \\ ${ }^{2}$ Russian University of Transport (MIIT), Russia \\ ${ }^{3}$ Plekhanov Russian University of Economics, 36 Stremmyanny Lane, Moscow, 117997, Russia. ORCID 0000-0001-5822-2325 \\ ${ }^{4}$ Plekhanov Russian University of Economics, 36 Stremmyanny Lane, Moscow, 117997, Russia; ORCID ID 0000-0003-1693- \\ 1646 \\ ${ }^{5}$ Bauman Moscow State Technical University, 5/1, 2-ya Baumanskaya str., Moscow, 105005, Russia; ORCID ID 0000-0002- \\ 9197-4219 \\ ${ }^{6}$ Financial University under the Government of the Russian Federation, 49, Leningradsky Prospekt, Moscow, 125993, Russia; \\ ORCID ID 0000-0002-8294-5205 \\ ${ }^{7}$ Russian State University of Tourism and Service, 99 Glavnaya str., Cherkizovo, Pushkinsky district, Moscow region, 141221, \\ Russia; ORCID ID 0000-0001-8880-8941
}

\begin{abstract}
The study aimed to analyze the possibilities of using blockchain technology to ensure technogenic safety and risk management. The article shows the relevance of using blockchain technology in risk management in such areas of activity as the Internet of Things and systems for tracking technogenic situations. Based on the analysis of scientific literature, a characteristic of blockchain technology, the relationship between blockchain technology, cyber-physical systems and the Internet of Things, as well as the possibilities of using blockchain technology in managing risks and manmade situations, are given. Classification of general blockchain risks that can affect a blockchain project is given. The need for the legal regulation of cyber risks associated with the use of blockchain technology is shown. It is concluded that the use of blockchain technology allows one to fully control the spatial movement of the manufactured goods. In combination with spatial positioning technologies, it eliminates the possibility of theft and leads to a decrease in the costs of controlling the distribution of products and an increase in the level of trust between participants in the exchange process.
\end{abstract}

Keywords - blockchain, cryptographic methods, technogenic safety, risk management, cyber-physical systems.

\section{INTRODUCTION}

Management of technogenic safety and risks is based on the theory of management of socio-economic systems, which, in the era of digitalization $[1,2]$, become distributed cyber-physical systems [3-5]. Thus, there is a question of information protection in distributed cyber-physical systems [6-9]. Blockchain technology can help us solve this problem [10-13].
The topic of the possibility of blockchain technology has been actively explored in recent years when cryptocurrencies have become widely used in the world. Depending on the functional application of blockchain technology, researchers point to different possibilities of this technology.

Researchers believe that the main directions of using blockchain technology in various spheres of human activity include:

- public administration, when blockchain allows maintaining decentralized state registers, in particular registers of ownership of land, real estate, etc. Using them, one can effectively manage any assets or information with high transparency of operations [14];

- public and private electronic document management [10];

- public opinion polls audit of conducted public procurement or supplies [15];

- protection of intellectual property based on smart contracts [16];

- agricultural sector, in particular, for maintaining a register of animal identification helping to trace livestock products from birth to the moment products are delivered to the energy retail network for the redistribution and exchange of surplus energy between network users [13];

- banking sector - for maintaining, for example, registers of bank guarantees [17];

- healthcare - for maintaining various registers (patients, medicines, medical equipment, etc.) [12]. 


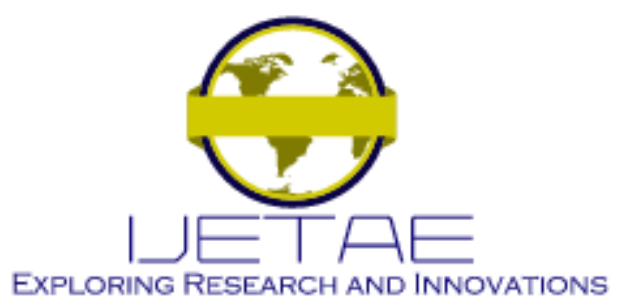

International Journal of Emerging Technology and Advanced Engineering

Website: www.ijetae.com (E-ISSN 2250-2459, Scopus Indexed, ISO 9001:2008 Certified Journal, Volume 11, Issue 12, December 2021)

Blockchain is a technology that allows storing information in distributed databases [15, 18]. This technology allows viewing the transaction history of all participants in the system. Usually, blockchain technology is associated with cryptocurrencies, but such unique qualities of the blockchain as transparency, decentralization, anonymity, equality, and security allow this technology to be used in other areas as well.

Blockchain is the name of a distributed database, which is a sequential chain of blocks built according to certain rules that contain some information [19, 20]. Each block contains a timestamp and a reference to the previous block. The blocks are linked chronologically and cryptographically. Cryptographic linking involves supporting rules for including new blocks in the chain and tracking attempts to modify existing blocks.

This approach is also called a distributed registry, referring to the fact that there is no centralized body (structure, regulator) that could dispose of such a chain of blocks at its discretion. Accordingly, the blockchain, as a database, does not have centralized control. This database, which is stored on the members' computers, is open to any member of the network. The complete history of data changes is stored in the system and protected from changes by cryptographic mechanisms.

Such a storage model also creates problems, which according to the authors have not yet been sufficiently investigated. Firstly, a full copy of all data, including the history of all changes, creates a large demand for memory resources. They are necessary for storing all these copies on the nodes involved in the data processing. Storing the history of changes leads to the fact that resource requirements will increase rapidly as the system develops. Further, the propagation of changes across all nodes significantly increases both the transaction time and its cost (in the sense of calculations). Naturally, there may also be activities for which the open storage of information in a distributed network may not be acceptable (for example, activities related to trade secrets or the storage of personal information). Therefore, the authors of the article consider it necessary in their research to highlight the risks and opportunities for their reduction when using blockchain technology, for example, in the field of Intra-things, in systems for tracking man-made situations, i.e. in those areas in which blockchain can soon be widely used in practice.

\section{METHODS}

Due to the novelty of the studied phenomenon and the research nature of the tasks set, a qualitative research approach was chosen.

The source base for writing the article was research by scientists on the possibilities and prospects of introducing blockchain technology in ensuring technological safety and risk management, publications in the field of social cybernetics and digital enterprise management, as well as materials on the Internet of Things technologies.

At the first stage of the study, a source base was formed that was adequate to the purpose of the study. When forming the research source base, the search for scientific research on the Internet was carried out using the following keywords: blockchain, technogenic safety, risk management, Internet of Things, social cybernetics, digital enterprise management.

At the second stage, an expert assessment on the Harrington scale of the reliability of the selected sources was carried out using an email survey of 13 Russian experts in the field of blockchain and risk management. According to the results of the expert assessment, the reliability of the sources was estimated at 0.72 points (high value).

The final source base consisted of articles from scientific journals (21 sources, $63.7 \%$ of the total amount of information), materials of scientific and practical conferences (11 sources, 33.3\%), and articles from scientific collections of articles (1 source, $3 \%$ ).

At the third stage of the study, the collected information was processed using the methods of theoretical generalization, comparative analysis, analysis, and synthesis, which made it possible to determine the essence of blockchain technology, the relationship of blockchain technology with cyber-physical systems and the Internet of Things. This allowed us to establish the possibilities of using blockchain technology in managing risks and manmade situations and the need for the legal regulation of cyber risks associated with the use of blockchain technology.

Based on the analysis of literature sources, the article provides recommendations on the feasibility of using blockchain technology to protect the information in the remote management of enterprises, as well as legislative regulation of blockchain use in the emergency prevention and response system. 


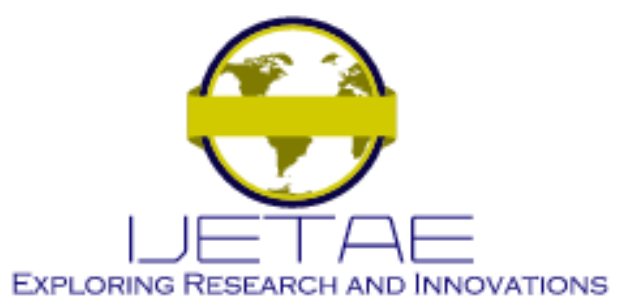

International Journal of Emerging Technology and Advanced Engineering

Website: www.ijetae.com (E-ISSN 2250-2459, Scopus Indexed, ISO 9001:2008 Certified Journal, Volume 11, Issue 12, December 2021)

\section{RESULTS}

\section{A. Cyber-physical systems, the Internet of Things, and blockchain}

The widespread use of Internet of Things technologies [17] and cyber-physical systems [5] has been followed by the emergence of social cybernetics as the new direction in management [5-7]. The introduction of digital management significantly influenced cyber-physical systems and the Internet of Things technologies in these spheres. As an inevitable consequence, the necessity of cybernetic control has increased.

The Internet of Things created an environment where physical objects interact and exchange data in a way free from human interference. The Internet of Things can be connected to the physical objects, not associated with computers and digital operations, including processing and generationg information.

Blockchain can be used in such a fundamental concept of Industry 4.0 as the Internet of Things. The Internet of Things can be used both in everyday life and business when providing services, collecting data remotely, obtaining instant market data, introducing self-service, etc. One of the main problems of this technology is the issue of protecting against system hacking and data leakage. As soon as the concept became popular, cybersecurity experts began to assess the risks from the thoughtless introduction of technology that is almost impossible to control $[9,21]$. The integration of blockchain into the Internet of Things will create a new computing segment in which data can be safely processed and analyzed while remaining private. This will provide increased security and privacy while using devices connected to the Internet [22-25]. In addition, the interaction between different machines will require certain monetary transactions, where cryptocurrencies can be used successfully.

\section{B. Blockchain, Risks, and Technogenic Situations}

Currently, the the following global trends define the probable digital transformation of the Unified State System of Emergency Prevention and Response [14, 16, 26]:

$\checkmark$ the emergence of low-cost, efficient digital remote access technologies;

$\checkmark$ cost-effective storage and processing of information;

$\checkmark$ the emergence of innovative designed developments in analytical technologies (e.x. big data).
The results of a quantitative risk assessment allow identifying potentially hazardous technologies and comparing alternative projects in this regard. Besides, the risk analysis can provide information on the dangerous risk factors operating on the site. Results of the risk assessment allow the creation of expert databases, which facilitate the decision-making and development of regulatory documents. Also, the quantitative risk assessment makes possible the identification of the priority areas for investments [4, 27].

Studies on technogenic risks and safety provide the base for the transition from traditional to innovative methods of risk assessment and management, including establishing the standards and limits for high-risk objects.

Development and justification of optimal activity programs designed to effectively implement security solutions. The main element of such activities is the process of optimal allocation of limited resources to reduce various types of risk to achieve the level of safety of the population and the environment that is only possible taking into account economic and social factors.

Rational protection measures are selected based on risk analysis and forecasting of possible emergencies. Therewith, the analysis is first carried out to determine the risk of destruction of individual infrastructure objects, then the risk of accidents and natural disasters for the territory as a whole, and finally, natural and man-made risks for the population of the studied territory. Rational protection measures are selected based on risk analysis and forecasting of possible emergencies. Therewith, the analysis is first carried out to determine the risk of destruction of individual infrastructure objects, then the risk of accidents and natural disasters for the territory as a whole, and finally, natural and man-made risks for the population of the studied territory.

Taking measures to reduce it by purposefully changing these factors, taking into account the effectiveness of the measures taken, is the essence of the risk management process.

The structure of the system for managing natural and man-made risks on a national scale or a certain territory includes the following main elements: establishing acceptable risk levels based on economic and social factors and building mechanisms for state safety regulation; monitoring the environment, analyzing the risk to the life of the population and predicting emergencies, conducting emergency rescue operations. 


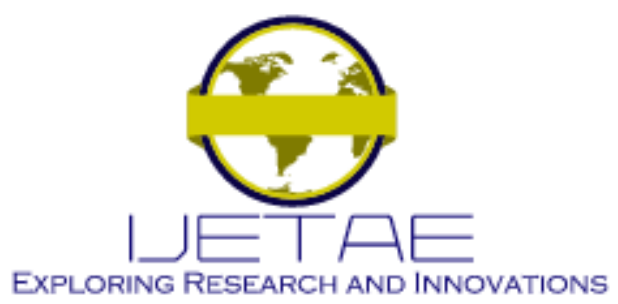

International Journal of Emerging Technology and Advanced Engineering

Website: www.ijetae.com (E-ISSN 2250-2459, Scopus Indexed, ISO 9001:2008 Certified Journal, Volume 11, Issue 12, December 2021)

It should be noted that the introduction of digital economy technologies in the field of environmental safety is an irreversible process. The scale and scope of the ongoing changes explain the sharp perception of innovation at the moment. The pace of development and dissemination of innovations in all areas is unprecedented.

We need to understand that the blockchain is also not completely secure, and precautions need to be taken to make it so.

The next stage of the risk management process after identification is the analysis of its nature and level. The following parameters are determined in the risk analysis:

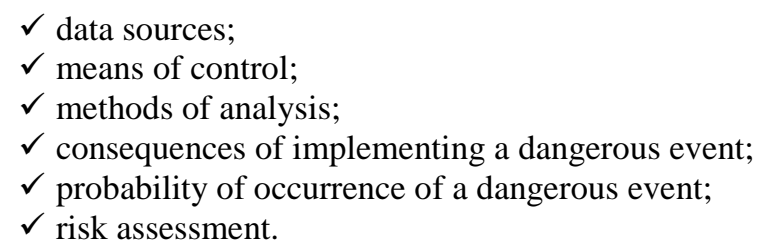

The following scales can be used for a qualitative (point) assessment of the risk level:

consequences scale;

probability scale.

After the risk assessment, the stage of its processing/modification by means of:

$\checkmark$ refusal of activity;

$\checkmark$ acceptance criteria;

$\checkmark$ eliminating the source of risk;

$\checkmark$ changes in its probability;

$\checkmark$ changes in its consequences;

$\checkmark$ sharing the risk with the other party.

Risk management includes the following steps:

$\checkmark$ defining risk processing goals;

$\checkmark$ identification and selection of risk treatment methods (taking into account costs, processing efficiency, and the level of residual risk);

$\checkmark$ development and implementation of a risk management plan.

The final stage of the risk management process is the monitoring of key risk indicators. Key risk indicators should:

$\checkmark$ be measured as a percentage, represent a number (number) or ratio;

$\checkmark$ be determined by comparable values for a certain period;

$\checkmark$ have basic values;

$\checkmark$ have inexpensive and easy (to interpret and control) data.
The issues of development and implementation of new technologies, satellite communications, and navigation, intelligent systems for monitoring and remote management of objects, ensuring public safety at major events and industrial facilities, creating situational centers, transmitting warning signals and emergency information about the dangers arising in natural and man-made emergencies, implementing a security system, show the existing capabilities of digital technologies in ensuring the safety of people in emergencies [26, 28-30].

\section{DISCUSSION}

In general, risk management is a system of measures, techniques, and methods that should affect the effectiveness of activities in the field of security.

According to researchers, the specific features of blockchain that provide risk management are transparency, validation, and automation.

The role of blockchain transparency in risk management is that all participants every time get replicated verified blockchain-based data. This eliminates the potential risks of possible mistakes in the distribution of information from a centralized database [15].

Speaking about the validation of blockchain technology, researchers [10, 29] note that data integrity has long been one of the risks in relation to any type of information. The information written to the blockchain after verification protected from the unauthorized changes or deletion, as changes in every copy of the blockchain need to match every other copy of this blockchain maintained by other stakeholders. This permanance of information in the blockchain makes it available to anyone interested to verify the origin of the data right up to the moment it is first loaded into the blockchain.

Blockchain can also automate certain actions [13] by introducing applications for pre-programmed instructions execution when certain information is verified on the blockchain. Automation of smart contracts not only reduces bottlenecks in information dissemination but also reduces the risk of non-compliance with regulatory requirements as it reduces the documentation or processes errors risks that can lead to critical situations [24, 30, 31].

At the same time, there are several risks directly related to the use of blockchain technology [11-13, 15], which can have an impact on any blockchain project, including: 


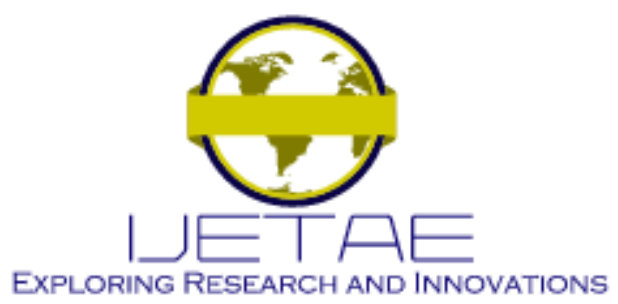

International Journal of Emerging Technology and Advanced Engineering

Website: www.ijetae.com (E-ISSN 2250-2459, Scopus Indexed, ISO 9001:2008 Certified Journal, Volume 11, Issue 12, December 2021)

Human risks. Even though the blockchain is characterized by complete decentralization, the chain nevertheless interacts with counterparties, which leads to new security threats. Thus, the interaction of any counterparty with the blockchain system occurs either through a computer or automated systems. When communicating through a computer, there is a possibility that credentials used to access the blockchain are stolen or compromised at the endpoints.

Also taking into account the legal regulations on data privacy — one of the most important problems associated with the blockchain or distributed ledger technology. It is clear that this technology has been developed, and it can play an important role in modern social infrastructure. In different countries and regions where data privacy rules apply, such as the European Union's General Data Protection Regulation, it is important to do the same for blockchain.

We are on the verge of formation in the complex industry of digital law and the basic direction of the digital economy program is legal regulation. As part of the implementation of the digital economy program, the nature and structure of management processes in the field of environmental safety will change, some routine procedures will be removed, replaced by artificial intelligence, robots. In addition, the generation of large amounts of information leads to a large number of cyber risks. All the problems that arise, such as regulatory legal regulation, need to be resolved as soon as possible.

Firstly, to develop and implement the concept of priority measures to improve legal regulation in the field of environmental safety in the framework of the development of the digital economy. It is necessary to determine: a list of the key existing legal restrictions that prevent digitalization in the field of environmental safety and to justify proposals for their elimination.

Secondly, to determine the priority basic legal concepts and institutions necessary for the digitalization of the sphere of environmental safety. Based on the formed list, regulatory legal acts should be adopted that eliminate key legal restrictions in certain branches of legislation that hinder the development of digitalization of the sphere of environmental safety within the digital economy.
Thirdly, the digitalization of the activities of the Unified State System of Emergency Prevention and Response both in the daily activities mode and in the "emergency" mode. This will require rebuilding and replacing analog (physical) systems for collecting and processing emergency data with technological systems. In a broad sense, it is the process of transferring to the digital environment the functions and activities of management processes previously performed by people and organizations. This will require amendments and additions to several federal laws, such as "On the protection of the population and territories from natural and man-made emergencies", "On emergency services and the status of rescuers", as well as regulatory legal acts of the Government of the Russian Federation regulating activities in areas of prevention and elimination of consequences of emergencies. These legislative and other regulatory legal acts should reflect the issues of creating modern favorable legal conditions for the introduction of additive technologies, blockchain technologies, big data technologies), universal technologies, the Internet of Things, virtual technologies, artificial intelligence technologies, etc. into the management process of the Unified State System of Emergency Prevention and Response.

\section{CONCLUSION}

Cybernetic management is a new step in the development of digital production and management technologies. The use of blockchain technology allows fully controlling the spatial movement of the manufactured goods, and in combination with spatial positioning, technologies eliminate the possibility of theft. Blockchain will help reduce the cost of controlling the distribution of products and increase the level of trust between participants in the exchange process.

\section{Acknowledgements}

This research was performed in the framework of the state task in the field of scientific activity of the Ministry of Science and Higher Education of the Russian Federation, project "Development of the methodology and a software platform for the construction of digital twins, intellectual analysis and forecast of complex economic systems", grant no. FSSW-2020-0008. 


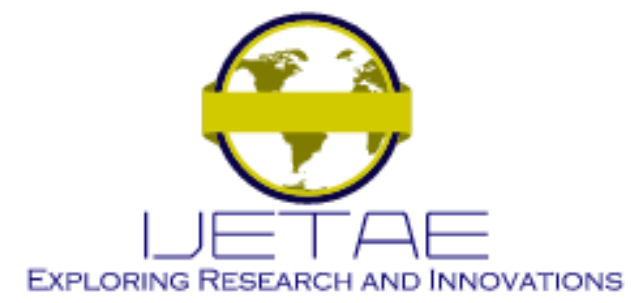

International Journal of Emerging Technology and Advanced Engineering

Website: www.ijetae.com (E-ISSN 2250-2459, Scopus Indexed, ISO 9001:2008 Certified Journal, Volume 11, Issue 12, December 2021)

\section{REFERENCES}

[1] S.K. Khaitan, and J. McCalley, "Design techniques and applications of cyber-physical systems: A Survey", IEEE Systems Journal, vol. 9, no. 2, pp. 1-6, 2014.

[2] A. Ben Ayed, "A conceptual secure blockchain-based electronic voting system", International Journal of Network Security and Its Applications, vol. 9, no. 3, pp. 1-9, 2017.

[3] A. Boiko, V. Shendryk, and O. Boiko, "Information systems for supply chain management: uncertainties, risks, and cybersecurity", Procedia Computer Science, vol. 149, pp. 65-70, 2019. https://doi.org/10.1016/J.PROCS.2019.01.108

[4] M. Kirilova, N. Maslov, and T. Astakhova, "Prospects for the introduction of blockchain technology into a modern system of education", International Journal of Open Information Technologies, vol. 6, no. 8, pp. 31-36, 2018.

[5] E.P. Fedorova, and E.I. Skobleva, "Application of blockchain technology in higher education", European Journal of Contemporary Education, vol. 9, no. 3, pp. 552-571, 2020.

[6] E.C. Ferrer, "The blockchain: a new framework for robotic swarm systems", in Proceedings of the future technologies conference. Cham, Switzerland: Springer, 2018, pp. 1037-1058

[7] I. Kirilchuk, V. Rykunova, L. Sevryukova, and V. Panskov, "Implementation of the incentive function of ecology payments under conditions of modernization of Russian environmental legislation", in Proceedings of the 19th International Multidisciplinary Scientific GeoConference SGEM 2019. Sofia, Bulgaria: Limited Liability Company STEF92 Technology, 2019, pp. 819-826.

[8] O.Ja. Kravets, S.V. Shaytura, A.M. Minitaeva, and I.V. Atlasov, "Analysis of routing processes in telecommunication networks with unsteady flows using Markov processes", IOP Conference Series: Materials Science and Engineering, vol. 862, 052005, 2020.

[9] S.V. Shaitura, A.S. Nedkova, L.M. Tyger, E.D. Goryacheva, N.O. Morozova, and L.V. Berketova, "Food security and catering", Revista Turismo Estudos and Práticas, no. S3, p. 11, 2020.

[10] O.G. Lebedinskaya, A.G. Timofeev, E.A. Yarnykh, N.A. Eldyaeva, and S.V. Golodov, "Features of the population's savings transformation into investments at the present stage", Advances in Intelligent Systems and Computing, vol. 622, pp. 510-518, 2018.

[11] L. Oveshnikova, O. Lebedinskaya, A. Timofeev, L. Mikheykina, E. Sibirskaya, and P. Lula, "Studying the sector of the Russian hightech innovations based on the global innovation index insead", Advances in Intelligent Systems and Computing, vol. 726, pp. 8796, 2019.

[12] E.P. Pankratov, V. Grigoryev, and O. Pankratov, "The blockchain technology in real estate sector: experience and prospects", IOP Conference Series: Materials Science and Engineering, vol. 869, 062010, 2020.

[13] R. Hanifatunnisa, and B. Rahardjo, "Blockchain-based e-voting recording system design (2018)", in Proceeding of 2017 11th International Conference on Telecommunication Systems Services and Applications, TSSA 2017. IEEE, 2018, pp. 1-6.

[14] S.V. Shaitura, K.V. Ordov, O.V. Pigoreva, I.V. Kosterina, D.A. Zyukin, and V.G. Gerasimova, "Problems of distance education", Revista Inclusiones, vol. 7, no. S4-1, pp. 24-38, 2020.
[15] S.V. Belim, and N.F. Bogachenko, "Distribution of cryptographic keys in systems with a hierarchy of objects", Automatic Control and Computer Sciences, vol. 50, no. 8, pp. 777-786, 2016.

[16] S.V. Shaitura, K.V. Ordov, I.G. Lesnichaya, Yu.D. Romanova, and S.S. Khachaturova, "Services and mechanisms of competitive intelligence on the internet", Espacios, vol. 39, no. 45, p. 24, 2018.

[17] S.V. Shaitura, Yu.P. Kozhaev, K.V. Ordov, T.A. Vintova, A.M. Minitaeva, and V.M. Feoktistova, "Geoinformation services in a spatial economy", International Journal of Civil Engineering and Technology, vol. 9, no. 2, pp. 829-841, 2018.

[18] S.A. Abeyratne, and R.P. Monfared, "Blockchain ready manufacturing supply chain using distributed ledger", International Journal of Research in Engineering and Technology, vol. 5, no. 9, pp. 1-10, 2016.

[19] S.V. Shaitura, F.M. Feoktistova, A.M. Minitaeva, L.A. Olenev, V.O. Chulkov, and Yu.P. Kozhaev, "Spatial geomarketing powered by big data", Revista Turismo Estudos and Práticas, no. S5, p. 13, 2020.

[20] S.V. Shaitura, Yu.P. Kozhaev, K.V. Ordov, A.V. Antonenkova, and N.A. Zhenova, "Performance evaluation of the electronic commerce systems", Espacios, vol. 38, no. 62, p. 11, 2017.

[21] S.V. Shaitura, A.M. Minitaeva, K.V. Ordov, and V.V. Shaparenko, "Virtual enterprises in a spatial economy", International Journal of Recent Technology and Engineering", vol. 7, no. 6, pp. 719-724, 2019.

[22] V.Ya. Tsvetkov, S.V. Shaytura, and K.V. Ordov, "Digital management railway", in Proceedings of the $1^{\text {st }}$ International Scientific and Practical Conference on Digital Economy (ISCDE 2019), Yekaterinburg, Russia. Atlantis Press, 2019, pp. 181185. https://doi.org/10.2991/iscde-19.2019.34

[23] V.Ya. Tsvetkov, S.V. Shaytura, and N.L. Sultaeva, "Digital enterprise management in cyberspace", in Proceedings of the 2nd International Scientific and Practical Conference "Modern management trends and the digital economy: from regional development to global economic growth" (MTDE 2020), Yekaterinburg, Russia. Atlantis Press, 2020, pp. 361-365. https://doi.org/10.2991/aebmr.k.200502.059

[24] V.Ya. Tsvetkov, "Cognitive information models". Life Science Journal, vol. 11, no. 4, pp. 468-471, 2014.

[25] M. Yemelyanov, N. Yemelyanova, and A. Nedelkin, "Neural network for decision support to determine the operating mode of lined equipment", MATEC Web of Conferences, vol. 224, 04005, 2018. https://doi.org/10.1051/matecconf/201822404005

[26] S.V. Shaitura, K.V. Ordov, and A.M. Minitaeva, "Digital learning methods for the digital economy", in Proceedings of the 1st International Scientific and Practical Conference on Digital Economy (ISCDE 2019), Chelyabinsk, Russia. Atlantis Press, 2019, pp. 606-611.

[27] S.V. Shaitura, A.M. Minitaeva, V.M. Feoktistova, and K.V. Ordov, "Blockchains in spatial data security", in CEUR Workshop Proceedings. Selected Papers of the X Anniversary International Scientific and Technical Conference on Secure Information Technologies (BIT 2019). CEUR Workshop Proceedings, 2019, pp. 70-74. 


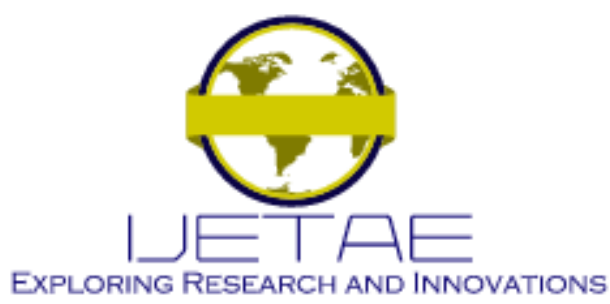

International Journal of Emerging Technology and Advanced Engineering

Website: www.ijetae.com (E-ISSN 2250-2459, Scopus Indexed, ISO 9001:2008 Certified Journal, Volume 11, Issue 12, December 2021)

[28] S.A. Timashev, "Unified quantitative criteria for the management of regional risk", in Safety, reliability, risk and life-cycle performance of structures and infrastructures. Proceedings of the 11th International Conference on Structural Safety and Reliability, ICOSSAR 2013. London, UK: CRC Press, 2013, pp. 165-172.

[29] V.Ya. Tsvetkov, "Information space, information field, information environment", European Researcher, vol. 8-1, no. 80, pp. 1416-1422, 2014.
[30] V.Ya. Tsvetkov, and A.A. Lobanov, "Big data as information barrier", European Researcher, vol. 7-1, no. 78, pp. 1237-1242, 2014.

[31] V.Ya. Tsvetkov, S.V. Shaitura, A.M. Minitaeva, V.M. Feoktistova, Yu.P. Kozhaev, and L.P. Belyu, "Metamodelling in the information field", Amazonia Investiga, vol. 9, no. 25, pp. 395-402, 2020. 